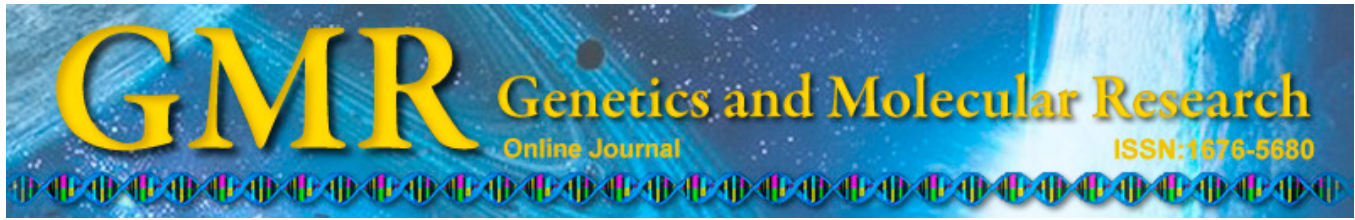

\title{
Stimulation of dendritic cell maturation and induction of apoptosis in lymphoma cells by a stable lectin from buckwheat seeds
}

\author{
C.Z. Bai ${ }^{1,2}$, H.J. Ji' ${ }^{2}$, M.L. Feng ${ }^{2}$, X.L. Hao ${ }^{2}$, Q.M. Zhong ${ }^{2}$, X.D. Cui ${ }^{1}$ and \\ Z.H. Wang ${ }^{1}$
}

${ }^{1}$ Key Laboratory for Chemical Biology and Molecular Engineering of Ministry of Education, Institute of Biotechnology, Shanxi University, Taiyuan, China

${ }^{2}$ Central Laboratory, Chinese Medicine Hospital of Shanxi Province, Taiyuan, China

Corresponding author: Z.H. Wang

E-mail: wangzhuanhua_1@163.com

Genet. Mol. Res. 14 (1): 2162-2175 (2015)

Received November 4, 2014

Accepted February 11, 2015

Published March 27, 2015

DOI http://dx.doi.org/10.4238/2015.March.27.3

\begin{abstract}
The present study aims to purify and characterize lectin from tartary buckwheat seeds and study its properties as well as biological activities to determine its possible biomedical applications in promoting maturation and proliferation of peripheral blood DCs derived from healthy donors and to study the effect of inducing apoptosis in human leukemia U937 cells. A novel tartary buckwheat lectin (TBL) protein, purified from tartary buckwheat seeds, showed a single band with a molecular mass of $65 \mathrm{kDa}$ in SDS-PAGE. The purified TBL hemagglutinated both human and animal erythrocytes and showed preference for blood type $\mathrm{O}$ and the rabbit blood type. TBL is active at up to $60^{\circ} \mathrm{C}$, and it is acid- and alkali-stable. TBL $(25 \mu \mathrm{g} / \mathrm{mL})$ combined with $5 \times 10^{-5} \mathrm{M}$ rhIL-4 promotes maturation and proliferation of peripheral blood dendritic cells (DCs), which is stronger than that promoted by rhTNF- $\alpha(20 \mathrm{ng} / \mathrm{mL})$. Exposure of DCs to $50 \mu \mathrm{g} /$ $\mathrm{mL}$ TBL for $48 \mathrm{~h}$ resulted in extensive upregulation of maturation
\end{abstract}


markers CD83 and CD40. These TBL-DCs were capable of producing several pro-inflammatory cytokines such as interleukin-10 (IL-10) and interleukin-12 (IL-12). The results of the treatment of human leukemia U937 cells with TBL in doses of $12.5,25,50$, and $100 \mu \mathrm{g} / \mathrm{mL}$ showed that tartary buckwheat-derived lectin induces apoptosis in a dosedependent manner. Our results encourage the use of tartary buckwheat and tartary buckwheat-derived lectins as immunopotentiating foods, targeted to strengthen immune responses and display a potential dietary supplement for cancer prevention.

Key words: Tartary buckwheat lectin, Dendritic cell, IL-10, IL-12, Leukemia

\section{INTRODUCTION}

Lectins are a diverse group of proteins of non-immune origin that interact reversibly and specifically with carbohydrates. These proteins are widely distributed in animals and plants. Lectins exhibit a variety of biological activities, such as anti-insect (Hilder et al., 1995), antifungal (Herre et al., 2004), anticancer (Dhuna et al., 2005), antiviral (Balzarini et al., 1992), and immunomodulatory activity (Rubinstein et al., 2004). They have various different functions in nature, the most important is information mediation in biological systems. Studies have shown that some plant lectins have several applications within the plant body, such as in pathogen defense mechanisms (Vandenborre et al., 2011), or outside the body, such as drug delivery (Bies et al., 2004), as well as a variety of diagnostic applications for a broad spectrum of diseases (Gemeiner et al., 2009). However, there are few reports on the function that promotes maturation and proliferation of dendritic cells (DCs) (Liu et al., 2011), and further study on the function of lectin on immune cells is warranted.

Tartary buckwheat grain is commonly used in the diets in Eastern Asian countries as an important functional food source (Kawakmi et al., 1995). Tartary buckwheat protein has high biological value due to a well-balanced amino acid composition and abundance of lysine and arginine. Previous studies have demonstrated that it has diverse pharmaceutical effects including antioxidant, immunoregulation, antihypertensive, hypolipidemic, and hypoglycemic activities (Tomotake et al., 2006; Cao et al., 2008). Especially, they have been reported to have high immunoregulation activities, and as strong antioxidants they act as scavengers for a wide range of reactive oxygen species and inhibitors of lipid peroxidation (Fabjan et al., 2003; Fujital et al., 2003). The immunoregulation activities of tartary buckwheat extract might be related to some functional proteins or flavonoids, although they remain largely unexplored (Jin and Wei, 2011).

DCs are the most potent antigen-presenting cells that play an important role in initiating adaptive immune responses and inducing antigen-specific T-lymphocyte responses. Immature DCs can capture antigens very efficiently by phagocytosis (Svensson et al., 1997), macropinocytosis, and endocytosis (Sallusto et al., 1995) through different cell surface molecules, e.g., Toll-like receptors (TLRs). The immunogenicity of DCs correlates with its functionally mature state, which is characterized by the increased expression and production of molecules involved in antigen processing and presentation and further interaction with $\mathrm{T}$ cells. Furthermore, the maturation process of DC can be induced by various cytokines (such as 
LPS, TNF- $\alpha$, IL-1 $\beta$, CD40L). It is reported that mature DCs are critical for a potent immune response against cancer cells following chemotherapy and radiotherapy (Vicari et al., 2002; Tesniere et al., 2008). DCs engulf apoptotic cancer cells through the recognition of apoptotic characteristics of tumor cells induced by treatment with anti-tumor agents such as mitoxantrone and doxorubicin, which can lead to maturation of DCs and a potent immune response in vivo (Obeid et al., 2007; Apetoh et al., 2008).

The present study aims to purify and characterize lectin from tartary buckwheat seeds and study its properties as well as biological activities to determine its possible biomedical applications in promoting maturation and proliferation of peripheral blood DCs derived from healthy donors and to study the effect of inducing apoptosis in human leukemia U937 cells. It may also provide insights for possible cancer prevention and immunotherapy.

\section{MATERIAL AND METHODS}

\section{Materials}

Tartary buckwheat seeds were obtained from Shanxi Academy of Agricultural Sciences, China. A Resource ${ }^{\mathrm{TM}} \mathrm{Q}(6.4 \times 30 \mathrm{~mm})$ anion exchange column and Superdex ${ }^{\mathrm{TM}} \mathrm{G} 75$ 10/300 GL gel filtration column were purchased from GE Healthcare (Uppsala, Sweden), RhIL-4 and GM-CSF were purchased from R\&D Systems (Minneapolis, MN, USA), and fetal bovine serum (FBS) and cell medium RPMI1640 were sourced from Sigma-Aldrich Co., Ltd., (St. Louis, MO, USA). Mouse anti-human CD83-PE monoclonal antibody, mouse anti-human CD40-FITC monoclonal antibody, mouse anti-human CD1a-FITC monoclonal antibody, and mouse anti-human HLA-DR monoclonal antibody were all products of Beckman Coulter Inc. (Brea, CA, USA). All solvents used in high performance liquid chromatography were of chromatography grade, and all other reagents were of the highest purity available.

\section{Extraction and purification of lectin from tartary buckwheat}

Tartary buckwheat seeds were prepared according to the protocol described in Cui and Wang, 2012. The seeds were ground and extracted in acetate buffer (ACE buffer, $\mathrm{pH}$ 5.0) at $4^{\circ} \mathrm{C}$ for $24 \mathrm{~h}$ and centrifuged at $10.000 \mathrm{~g}$ for $30 \mathrm{~min}$ at $4^{\circ} \mathrm{C}$. Solid (NH4) $\mathrm{SO}_{4}$ was slowly added to the supernatant to $80 \%$ saturation and continuously stirred for $4 \mathrm{~h}$. The precipitate was collected by centrifugation at $12,000 \mathrm{~g}\left(30 \mathrm{~min} ; 4^{\circ} \mathrm{C}\right)$, and then re-dissolved in $20 \mathrm{mM}$ Tris- $\mathrm{HCl}$ buffer $(\mathrm{pH} 7.0)$ and centrifuged at $10,000 \mathrm{~g}\left(30 \mathrm{~min} ; 4^{\circ} \mathrm{C}\right)$. The clear supernatant was used to determine the protein content and hemagglutinating activity. Pure TBL was obtained in two chromatographic steps with Resource ${ }^{\mathrm{TM}} \mathrm{Q}$ anion exchange column and Superdex ${ }^{\mathrm{TM}} 75$ 10/300 GL gel filtration column using an AKTA Purifier (GE Healthcare). The TBL protein concentration was determined according to the method described by Bradford (1976) with bovine serum albumin as a standard.

\section{Sodium dodecyl sulfate-polyacrylamide gel electrophoresis (SDS-PAGE)}

SDS-PAGE was performed according to the method of Laemmli (1970) using $12.5 \%$ separating and $4 \%$ stacking gel. The gels were stained with Coomassie Brilliant Blue R-250 (Pharmacia, Uppsala, Sweden). The molecular weight of individual protein bands was deter- 
mined using a GeneGenius densitometric imaging system (Syngene, Cambridge, UK) with protein standards.

\section{Hemagglutinating activity assay of TBL}

Serial two-fold dilutions of lectin solution $(25 \mu \mathrm{L})$ in microtiter v-plates were prepared with different types of $2 \%$ red blood cell suspensions in saline, separately. The plates were incubated at room temperature until the red blood cells in the blank (with no protein sample added) had fully settled at the bottom of the well and appeared as red sediment. Formation of plaques of agglutinated red blood cells indicated hemagglutinating activity. Specific activity of TBL is reciprocal of the highest dilution of the protein sample inducing hemagglutination per milligram protein, expressed as $2^{\mathrm{n}}$ ( $\mathrm{n}$ is the last well of inducing hemagglutination) (Yagi et al., 2002). All experiments were performed in accordance with the guidelines established by the National Institutes of Health for the care and use of laboratory animals and were approved by the Animal Care Committee of the Shanxi University, Taiyuan, China, and Chinese Academy of Medical Sciences, Beijing, China.

\section{Temperature and pH stability on hemagglutinating activity of TBL}

For the $\mathrm{pH}$ stability test, the TBL was dissolved in solutions at different $\mathrm{pH}$ values: $\mathrm{pH}$ 2.4-3.0 in solutions with $\mathrm{HCl}$ and $\mathrm{pH}$ 11.7-12.2 in solutions with $\mathrm{NaOH}$. After incubation at room temperature for $30 \mathrm{~min}$, the solutions were neutralized, and assay of hemagglutinating activity was performed as described above (Chan and $\mathrm{Ng}, 2013$ ). For the heat stability test, the TBL solutions were heated at different temperatures $\left(25^{\circ} \mathrm{C}-80^{\circ} \mathrm{C}\right)$ for 30 min and immediately cooled on ice. Cooled solutions were then assayed for hemagglutinating activity (Nakagawa et al., 1996).

\section{Isolation of peripheral blood mononuclear cells (PBMCs)}

The study was conducted according to the principles of the Declaration of Helsinki. All study participants provided written informed consent. Peripheral blood mononuclear cells were isolated by the density-gradient centrifugation method using Ficoll-Paque (Pharmacia Biotech, Stockholm, Sweden). The cells were washed twice with phosphate buffered saline (PBS), and then suspended in RPMI 1640 (Gibco Laboratories, Grand Island, NY, USA) supplemented with 10\% fetal bovine serum (FBS) (Hyclone, Oud-Beijerland, Netherlands), 2 $\mathrm{mM}$ glutamine (Sigma), $100 \mathrm{U} / \mathrm{mL}$ penicillin $\mathrm{G}$ (Sigma), and $100 \mu \mathrm{g} / \mathrm{mL}$ streptomycin (Sig$\mathrm{ma})$, and placed in $75-\mathrm{cm}^{2}$ flasks.

\section{Generation of human monocyte-derived dendritic cells (MoDCs)}

After $2 \mathrm{~h}$ of adherence of PBMCs to the flask and two PBS washes, the adherent cells were used for generation of MoDCs following the method described by Tsai et al. (2010). The adherent cells were cultured in RPMI1640 medium supplemented with 1000 U/mL GM-CSF (Peprotech, Rocky Hill, NJ, USA) and 500 U/ml of IL-4 (Peprotech) for 7 days. Cultured cells were harvested as DCs and used for subsequent experiments. 


\section{TBL-induced PBMCs proliferation assay}

TBL-induced PBMCs proliferation was measured with a cell counting kit (CCK-8 kit; Dojindo). PBMCs $\left(5 \times 10^{3}\right.$ cells/well) were plated on a 96-well plate and treated with TBL at the concentrations of $10,12.5,25,50$, and $200 \mu \mathrm{g} / \mathrm{mL}$; each group was present in triplicate. The control group was prepared by adding equal number of PBMCs and equal volume of medium. Each day, aliquots of $100 \mu \mathrm{L}$ of medium without serum and $10 \mu \mathrm{L}$ of CCK- 8 were mixed and added to each well. After incubation at $37^{\circ} \mathrm{C}$ for $4 \mathrm{~h}$, the OD value was assessed by spectrophotometry at a wavelength of $570 \mathrm{~nm}$.

\section{Effect of TBL on the maturation of DCs}

Immature DCs were harvested after 7 days of culture, and part of the cells were identified by the flow cytometry method. The rest were equally divided into two wells, DCs in the test group were treated with TBL at a final concentration of $50 \mu \mathrm{g} / \mathrm{mL}$, while that in the control group were treated with rhTNF- $\alpha$ at a final concentration of $20 \mathrm{ng} / \mathrm{mL}$, and the cells were cultured for 2 days until maturation. The number, growth, and morphological characteristics of DCs were observed every day using inverted phase contrast microscope (Olympus, Tokyo, Japan).

\section{Flow cytometric analysis}

Mature DCs from the test group and the control group were harvested for cell phenotype identification. The cells were incubated for $30 \mathrm{~min}$ with monoclonal antibodies against FITCHLA-DR, APC-CD1 $\alpha$, PE-CyTM FITC-CD40, and PE-CD83. FITC-IgG1 and APC-Ig G2 were used for isotype controls. All samples were analyzed by an FC 500 Flow Cytometry system (Beckman Coulter, Brea, CA, USA), and results were expressed as mean fluorescence intensity values after subtracting the mean fluorescence intensity obtained with the control antibody.

\section{Quantification of cytokine production}

The enzyme-linked immunosorbent assay (ELISA kits, R\&D Systems) was used to assay the protein levels of interleukin-12 (IL-12) and interleukin-10 (IL-10) in the cell culture supernatant according to the manufacturer protocol. DCs were activated with $50 \mu \mathrm{g} / \mathrm{mL}$ TBL or $20 \mathrm{ng} / \mathrm{mL} \mathrm{TNF}-\alpha$. After $48 \mathrm{~h}$ of stimulation, cells were centrifuged and the supernatant was used for ELISA analysis. All samples were tested in triplicate for standard curves.

\section{Mixed-lymphocyte reaction (MLR) assay}

MoDCs were incubated for $48 \mathrm{~h}$ with TBL $(50 \mu \mathrm{g} / \mathrm{mL})$ or TNF- $\alpha(20 \mathrm{ng} / \mathrm{mL})$. Mature MoDCs were harvested and then treated with Mitomycin C (MMC; Sigma) $(50 \mu \mathrm{g} / \mathrm{mL})$. CD3 ${ }^{+}$ $\mathrm{T}$ cells were isolated from adult peripheral blood mononuclear cells using a $\mathrm{CD}^{+} \mathrm{T}$ cell isolation kit (MACS; Miltenyi Biotec Inc., Bergisch Gladbach, Germany). T cells ( 1 x $\left.10^{6}\right)$ were added to the 96-well plate, and using immature DC as the control group and mature DC as the TBL- and rhTNF- $\alpha$-induced groups, the DC cells were divided into sets of $0.5 \times 10^{3}, 2.5 \times 10^{3}$, $5 \times 10^{3}$, and $10 \times 10^{3}$ cultured with T cells, and they were co-cultured for $72 \mathrm{~h}$. Lymphocyte activation marker of CD69 and BrdU were analyzed using flow cytometry, and the innate T 
lymphocyte activation rate was calculated.

\section{Apoptosis studies of TBL on lymphoma cells}

We validated any potential toxicity of the TBL used in our study by an FC 500 Flow Cytometry system (Beckman Coulter) using an Apoptosis Detection Kit (Sigma) according to the manufacturer protocol. U937 cells were seeded in RPMI-1640 containing 10\% FBS and treated with 0 (control), 12.5, 25, 50, and $100 \mu \mathrm{g} / \mathrm{mL}$ TBL, and $50 \mu \mathrm{g} / \mathrm{mL}$ BSA for $48 \mathrm{~h}$. The percentages of live cells, dead cells, and cells in the early apoptotic process were determined by staining with annexin V-FITC conjugate and propidium iodide.

\section{Statistical analysis}

The data were analyzed by one-way and two-way analysis of variance followed by the Newman-Keuls test when appropriate. Statistically significant difference between experimental groups was assessed by a two-tailed Student $t$-test. The results are reported as means $\pm \mathrm{SD}$. A P value of less than 0.05 was considered to be statistically significant.

\section{RESULTS}

\section{BL properties and hemagglutination assay}

Hemagglutinating activity was determined in elutions between 35.0 and $40.0 \mathrm{~mL}$ with $1 \mathrm{M} \mathrm{NaCl}$ using FPLC-gel filtration chromatography on AKTA purifier. Purified TBL appeared as a single band with an approximate molecular weight of $65 \mathrm{kDa}$ in SDS-PAGE (Figure 1).

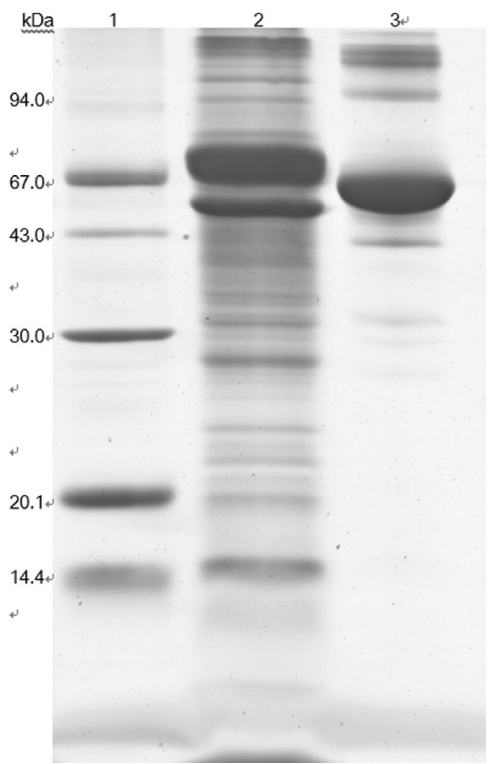

Figure 1. Results of SDS-APGE. Lane $1=$ molecular weight marker; lane 2 = fraction purified by Resource ${ }^{\mathrm{TM}} \mathrm{Q}$ gel filtration; lane 3 = fraction purified by Superdex TM 75 10/300 GL gel filtration. 
TBL agglutinated four types of human erythrocytes and three types of animal erythrocytes. The hemagglutination activity of TBL was high (Table 1 ); the agglutination titer was $2^{8}-2^{10}$. TBL had moderate thermostability. It retained full hemagglutinating activity at temperatures up to $62^{\circ} \mathrm{C}$, but the activity dropped abruptly when the temperature was elevated from $64^{\circ} \mathrm{C}$ to $70^{\circ} \mathrm{C}$, and vanished at $80^{\circ} \mathrm{C}$ (Table 2). On the other hand, TBL showed fairly high pH stability. Hemagglutinating activity was preserved at $\mathrm{pH} 2$ to 13 , while the activity was halved at $\mathrm{pH} 0$ to 1 and completely eliminated at $\mathrm{pH} 14$ (Table 3 ).

Table 1. Hemagglutination activity of TBL on four types of human and three types of animal erythrocytes.

\begin{tabular}{lc}
\hline Erythrocyte & Titer of agglutination \\
\hline Human (A type) & $2^{8}$ \\
Human (B type) & $2^{9}$ \\
Human (AB type) & $2^{8}$ \\
Human (O type) & $2^{10}$ \\
Rat & $2^{9}$ \\
Mouse & $2^{9}$ \\
Rabbit & $2^{10}$ \\
\hline
\end{tabular}

Table 2. Thermostability activity of TBL.

\begin{tabular}{lc}
\hline Temperature $\left({ }^{\circ} \mathrm{C}\right)$ & Titer of agglutination activity \\
\hline 25 & $2^{10}$ \\
40 & $2^{10}$ \\
50 & $2^{9}$ \\
60 & $2^{8}$ \\
70 & $2^{5}$ \\
80 & 0 \\
\hline
\end{tabular}

Initial concentration was $1 \mathrm{mg} / \mathrm{mL}, 2^{8}=3.91 \mu \mathrm{g} / \mathrm{mL} ; 2^{9}=1.95 \mu \mathrm{g} / \mathrm{mL} ; 2^{10}=0.97 \mu \mathrm{g} / \mathrm{mL}$.

\section{Table 3. Acid or base stability of TBL.}

\begin{tabular}{lcc}
\hline $\mathrm{C}$ (acid or base)/M & PH value & Titer of agglutination \\
\hline $\mathrm{NaOH}, 0.03$ & 11.7 & $2^{10}$ \\
$\mathrm{NaOH}, 0.06$ & 11.9 & $2^{9}$ \\
$\mathrm{NaOH}, 0.12$ & 12.0 & $2^{8}$ \\
$\mathrm{NaOH}, 0.24$ & 12.2 & $2^{8}$ \\
$\mathrm{HCl}, 0.03$ & 3.0 & $2^{8}$ \\
$\mathrm{HCl}, 0.06$ & 2.8 & $2^{8}$ \\
$\mathrm{HCl}, 0.12$ & 2.6 & $2^{7}$ \\
$\mathrm{HCl}, 0.24$ & 2.4 & $2^{7}$ \\
\hline
\end{tabular}

Initial concentration was $1 \mathrm{mg} / \mathrm{mL}, 2^{9}=1.95 \mu \mathrm{g} / \mathrm{mL} ; 2^{10}=0.97 \mu \mathrm{g} / \mathrm{mL}$.

\section{Proliferation of PBMCs with various concentrations of TBL}

During the 4 days of observations, there was no significant difference in the number of PBMCs between the group treated with TBL concentration of $50 \mu \mathrm{g} / \mathrm{mL}$ and the control group (Figure 2), indicating that TBL has no adverse effect on the proliferation of PBMCs at the concentration of $50 \mu \mathrm{g} / \mathrm{mL}$. Therefore, this concentration of TBL was chosen for co-culture with immature DCs. 


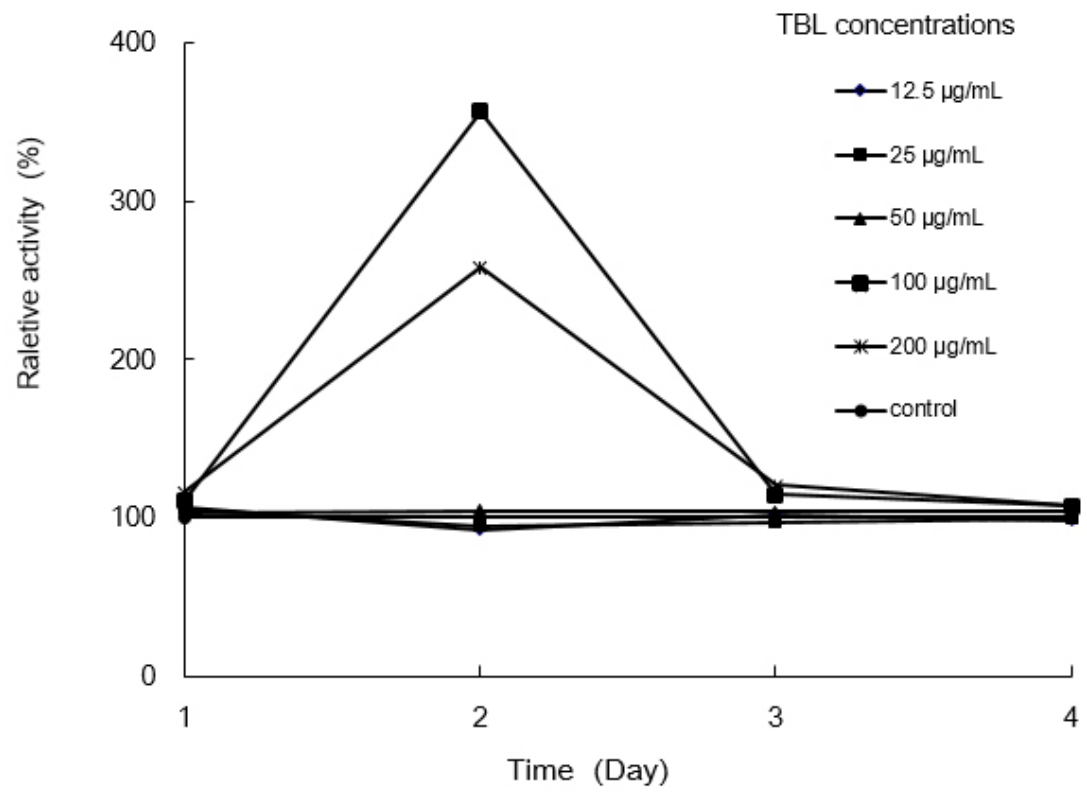

Figure 2. Proliferation effect of peripheral blood mononuclear cells (PBMCs) treated with various concentrations of lectin.

\section{Effect of TBL on DCs morphology}

To investigate whether TBL induces peripheral blood (PB) DCs maturation, we observed the morphology of DCs under the inverted phase contrast microscope. Compared with the control group, the number of DCs after their incubation with $50 \mu \mathrm{g} / \mathrm{mL}$ TBL significantly increased, and with increased apophysis, these cells were irregular and presented the evidence of dendritic processes, which characterizes the typical maturation process in DCs (Figure 3A and B).

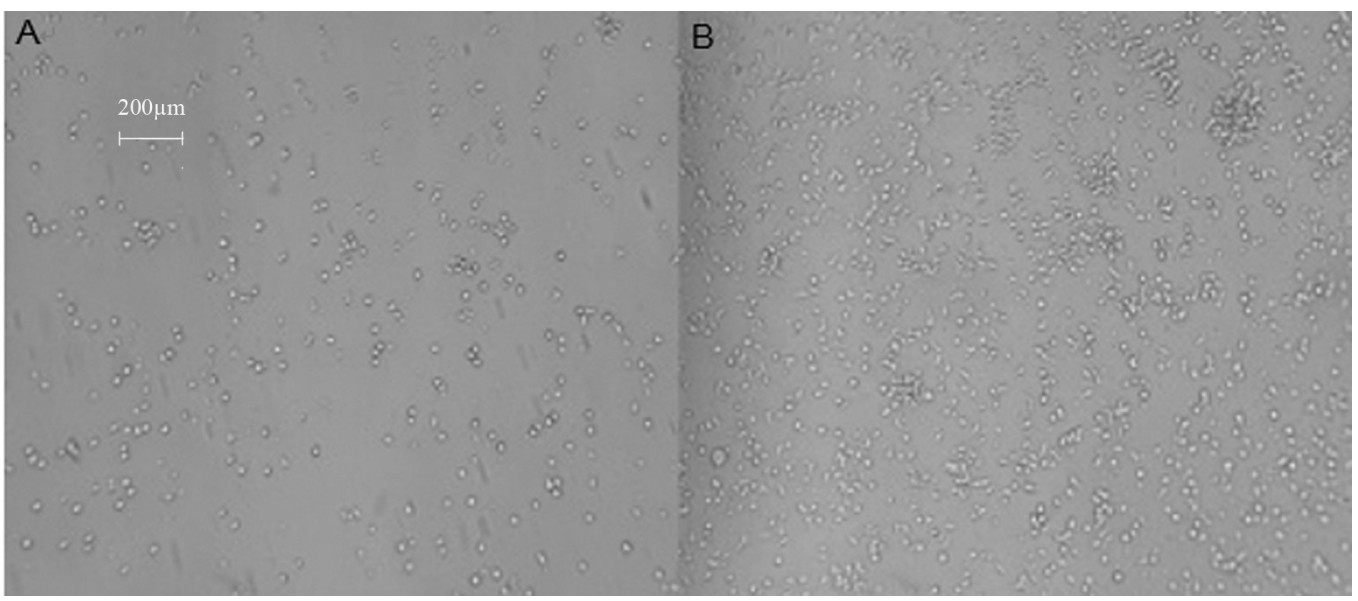

Figure 3. Biological characterization of lectin treated PBDCs. A. Control; B. treatment. 


\section{TBL causes extensive upregulation of DC maturation markers}

We measured the expression of PBDC maturation markers such as CD1 $\alpha$, HLA-DR, CD40, and CD83 using TNF- $\alpha$ as a positive control. Untreated PBDCs expressed basal levels of CD1 $\alpha(88.7 \pm 0.5 \%)$ and HLA-DR $(91.5 \pm 0.6 \%)$, indicated the high purity of DCs, but still in the immature phase, whereas the expression of CD40 and CD83 was low at $26.3 \pm 0.7$ and $28.4 \pm 0.4 \%$ respectively. As we expected, the amount of CD83 $(85.1 \pm 0.7 \%)$ in TBL-treated group was higher than in PBDCs treated with TNF- $\alpha(56.4 \pm 0.4 \%)$. These results indicate that $50 \mu \mathrm{g} / \mathrm{mL}$ TBL can upregulate the expression of CD83 $(\mathrm{P}<0.05)$, a known marker of DC maturation, and thus promote the maturation of DCs in more effective way (Table 4).

Table 4. Comparison of maturation DCs phenotypes (\%, means $\pm \mathrm{SD})$.

\begin{tabular}{llllc}
\hline Group & CD1 $\alpha$ & HLA-DR & CD40 & CD83 \\
\hline Control & $68.7 \pm 0.5$ & $97.5 \pm 0.6$ & $55.3 \pm 0.7$ & $56.4 \pm 0.4$ \\
Test & $69.2 \pm 0.4^{*}$ & $97.2 \pm 0.2^{*}$ & $76.2 \pm 0.5^{*}$ & $85.1 \pm 0.7^{*}$ \\
\hline
\end{tabular}

Text group compared with control group, *significant difference at $\mathrm{P}<0.05$. The number of DCs in the test group was $5.8 \times 10^{5} \pm 0.8 \times 10^{3}$, and in the control group there were only $5.3 \times 10^{5} \pm 1.1 \times 10^{3}$.

\section{Activation of DCs with TBL induces production of certain pro-inflammatory cytokines}

DCs secrete various cytokines (IL-6, IL-10, IL-12, and TNF- $\alpha$ ), which in turn induce numerous cellular and molecular events needed by various immune cells to elicit antigenspecific immune responses. ELISA was employed to detect the IL-12 and IL-10 content in the supernatant of DCs following 48-h-long maturation induction. The secretion of IL-10 and IL-12 stimulates the proliferation and differentiation of Th2 and Th1 cells, respectively (Trinchieri 2003, 2007). The secretion of IL-10 and IL-12 in TBL-treated PBDCs was significantly increased in a dose-dependent manner (Figure 4A and B).
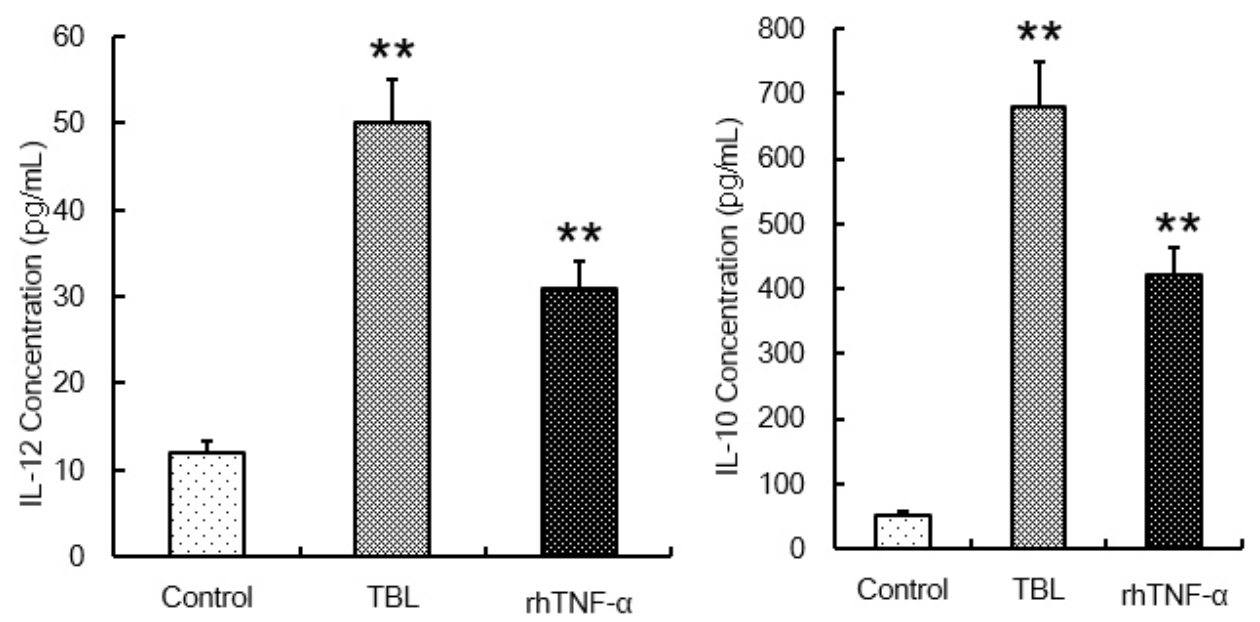

Figure 4. Lectin induced cytokines secretion by PBDCs. PBDCs were treated with $50 \mu \mathrm{g} / \mathrm{mL}$ lectin or rhTNF- $\alpha$ for $48 \mathrm{~h}$. ELISA assay was used to test the levels of IL-12 (left) and IL-10 (right) in lectin treated PBDCs. (**indicates $\mathrm{P}<0.01$ compared with control). 


\section{PBDCs activated with TBL induce and promote T lymphocytes activation}

Mature DCs demonstrate high expression of costimulatory molecules and are potent to activate and stimulate the proliferation of T lymphocytes ( $\mathrm{Li}$ et al., 2012). To characterize the effect of TBL-treated PBDCs on the interaction with T cells, we performed an allogeneic MLR assay using human $\mathrm{CD}^{+} \mathrm{T}$ cells. $\mathrm{CD}^{+} \mathrm{T}$ cells co-cultured with TBL-treated DCs proliferated to greater extent than $\mathrm{CD}^{+} \mathrm{T}$ cells co-cultured with TNF- $\alpha$-treated DCs after 72-h incubation period. Using flow cytometry to analyze the lymphocyte activation markers CD69 and BrdU, we calculated the primary T lymphocyte activation rate (Figure 5). We then investigated IFN- $\gamma$ and IL-4 productions in $\mathrm{CD}^{+}$T cells activated with TBL-treated PBDCs. $\mathrm{CD}^{+} \mathrm{T}$ cells primed with TBL-treated PBDCs produced significantly higher levels of IFN- $\gamma$ than cells primed with untreated PBDCs (Figure 6A, B).

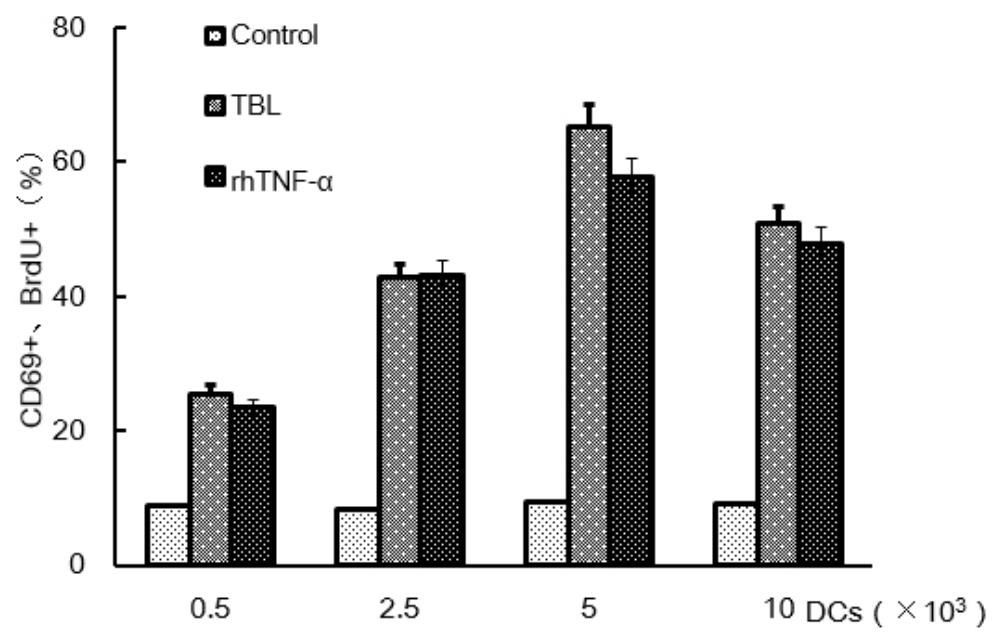

Figure 5. Lectin treated PBDCs induces activations of T lymphocytes. Flow cytometry was used to analyze the lymphocyte activation marker of CD69 and BrdU. * and **indicate $\mathrm{P}<0.05$ and $\mathrm{P}<0.01$, respectively, compared with control.
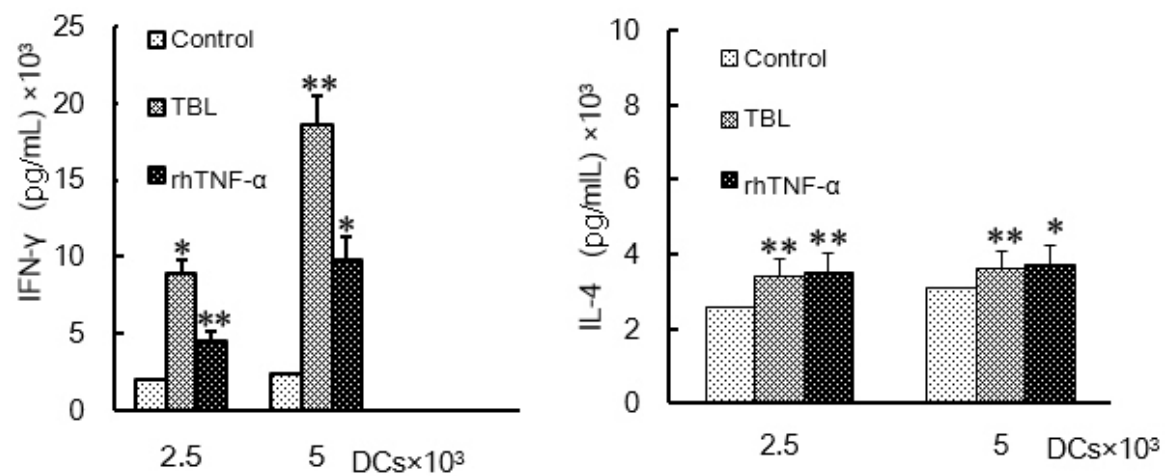

Figure 6. Lectin treated PBDCs induces cytokine secretion of T lymphocytes. Culture supernatants were harvested after $72 \mathrm{~h}$, and cytokine levels were measured by ELISA. Results are representative of three experiments. * and **indicate $\mathrm{P}<0.05$ and $\mathrm{P}<0.01$, respectively, compared with control. 


\section{TBL-treated U937 cells cause cells apoptosis}

After we investigated the effect of TBL on normal cells, we decided to study how TBL affects tumor cells. For this purpose, we cultured U937 with various concentrations of TBL and $50 \mu \mathrm{g} / \mathrm{mL}$ BSA for $48 \mathrm{~h}$. The addition of TBL at concentrations of $12.5 \mu \mathrm{g} / \mathrm{mL}$ and higher to U937 cell cultures significantly increased the number of dead or apoptotic cells compared with either non-treated or BSA-stimulated control U937 cells (Figure 7A-F).
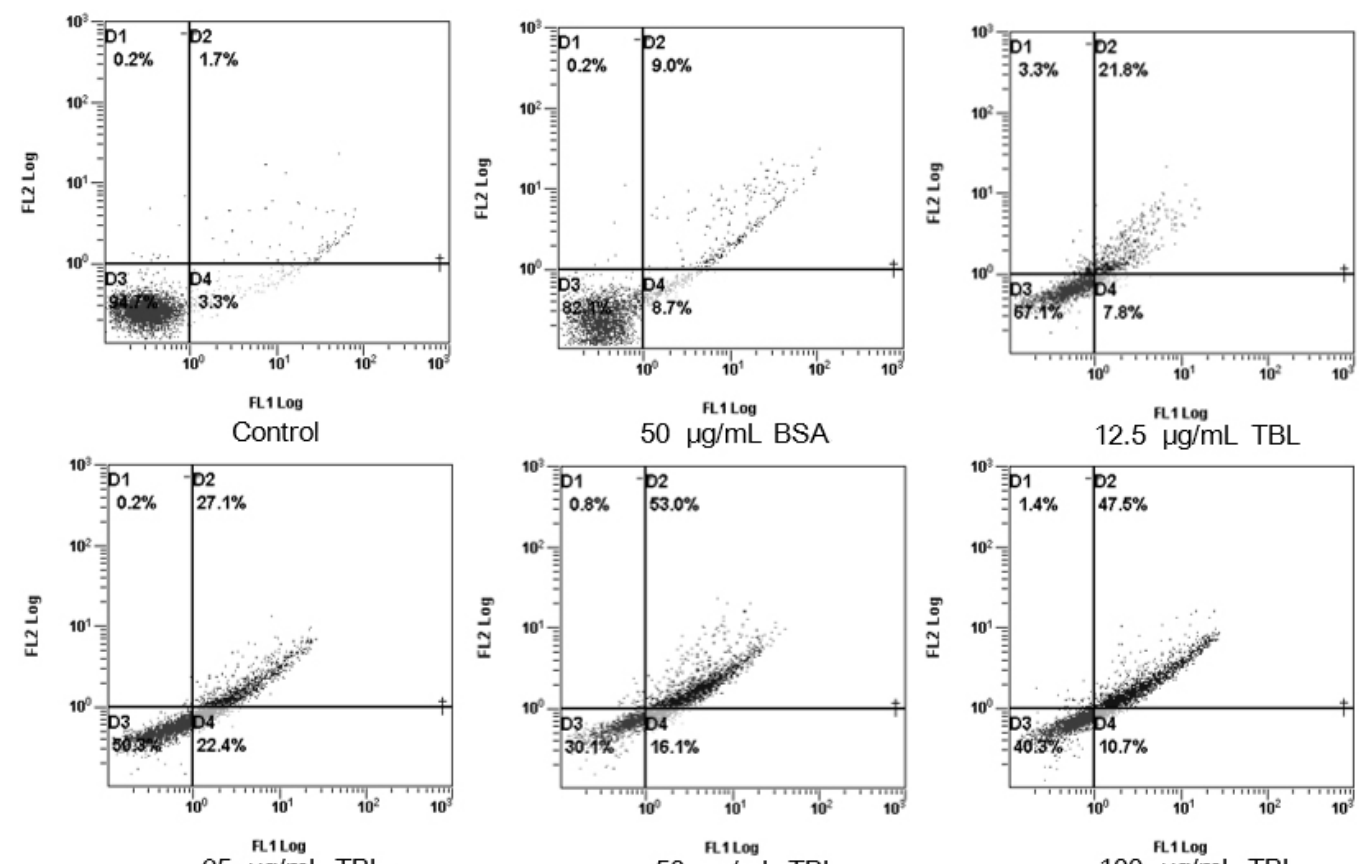

$25 \mu \mathrm{g} / \mathrm{mL}$ TBL

$50 \mu \mathrm{g} / \mathrm{mL}$ TBL

$100 \mu \mathrm{g} / \mathrm{mL}$ TBL

Figure 7. Lectin treated U937 cells causes their apoptosis. U937 cells were either not treated or they were stimulated with various concentrations of lectin or with $50 \mu \mathrm{g} / \mathrm{mL}$ BSA. After $48 \mathrm{~h}$, U937 cells were stained with annexin and propidium iodide and samples were analyzed with flow cytometry for early detection of apoptotic and dead cells. Results shown are representative of three independent experiments. Numbers in quadrants represent the percentage of annexin-positive or propidium iodide-positive cells.

\section{DISCUSSION}

Tartary buckwheat-derived lectins are characterized by moderate thermo- and $\mathrm{pH}$ stability and exhibited agglutination toward four types of human erythrocytes and three types of animal erythrocytes. TBL retained its full hemagglutinating activity in the broad range of $\mathrm{pH}$ 2 to 13, while the activities of some other lectins were reported to diminish above $\mathrm{pH} 9$ (Kaur et al., 2005; Vaz et al., 2010).

In the present study, we evaluated the immunomodulatory effects of TBL, which exhibit both DC maturation-inducing activity and apoptosis-inducing activity on human leukemia U937 cells. At a concentration of $25 \mu \mathrm{g} / \mathrm{mL}$, TBL induces functional maturation of DCs as well as the extensive phenotypic expression of DCs, which are subsequently capable of 
stimulating efficient T cell responses. Moreover, TBL can increase the cytokines of IL-12 and IL-10 production. IL-12 is a functional DC maturation marker and is involved in the differentiation of naïve T cells into Th1 cells (Kaliński et al., 1997). IL-10 is a cytokine with pleiotropic effects in immunoregulation and inflammation, and it also has stimulatory effect toward Th2 cells and stimulates B cell maturation and antibody production. Production of cytokines such as IL-12 and IL-10 during the DCs maturation process can influence DC induction of the Th1 or Th2 immune response. Previous reports have shown the immunomodulatory effects of lectin on DCs. $N$-acetyl-D-galactosamine binding lectin from mistletoe (Viscum album) has also been shown to induce the maturation of DCs (Stein et al., 2002a,b). A galactose- $N$-acetylD-galactosamine lectin (Gal-lectin) from Entamoeba histolytica has also been shown to induce maturation and activation of DCs as well as Th1 cytokine production (Ivory and Chadee, 2007). Besides, Gal-lectin also activated macrophages in which lectin increased gene transcription and surface expression of TLR2 (Kammanadiminti et al., 2004).

In addition to its DC maturation activity, tartary buckwheat-derived lectins also induce apoptosis in human leukemia U937 cells. Tumor is a disease state characterized by a loss of apoptosis. Apoptosis is the process of programmed cell death through a tightly controlled program that plays important roles in many normal processes (Reed, 2001). Thus, application of TBL may represent a useful strategy to modulating apoptosis in the therapy or prevention and management of cancer, and it has been a new target for drug discovery based on innovative mechanism in apoptotic induction. Compounds that induce apoptosis to block or suppress the proliferation of tumor cells are considered to have potential as antitumor agents (Frankfurt and Krishan, 2003). Further investigation of the immunopotentiating activity of tartary buckwheat-derived lectins in animal cancer models is warranted.

In summary, we purified lectin from tartary buckwheat and for the first time, characterized its notable biological properties such as maturation-inducing DCs and apoptosis-inducing human leukemia cells activities. These results provide an important basis for further studies on the pharmacological activity of tartary buckwheat and its components and the potential of TBL as an adjuvant in cancer prevention and immunotherapy.

\section{ACKNOWLEDGMENTS}

Research supported by the Natural Science Foundation of China (Grants \#31171659, \#81173574) and the Shanxi Provincial Experimental Animal Special Funds (Grant \#2011K04). We gratefully acknowledge the kind discussions and cooperation of Chinese Medicine Hospital of Shanxi Province. We also thank all the staff of the Institute of Biotechnology for their helpful technical assistance.

\section{REFERENCES}

Apetoh L, Tesniere A, Ghiringhelli F, Kroemer G, et al. (2008). Molecular interactions between dying tumor cells and the innate immune system determine the efficacy of conventional anticancer therapies. Cancer Res. 68: 4026-4030.

Balzarini J, Neyts J, Schols D, Hosoya M, et al. (1992). The mannose-specific plant lectins from Cymbidium hybrid and Epipactis helleborine and the (N-acetylglucosamine)n-specific plant lectin from Urtica dioica are potent and selective inhibitors of human immunodeficiency virus and cytomegalovirus replication in vitro. Antiviral Res. 18: 191-207.

Bies C, Lehr CM and Woodley JF (2004). Lectin-mediated drug targeting: history and applications. Adv. Drug Deliver. Rev. 56: 425-435. 
Bradford MM (1976). A rapid and sensitive method for the quantitation of microgram quantities of protein utilizing the principle of protein-dye binding. Anal. Biochem. 72: 248-254.

Cao W, Chen WJ, Suo ZR and Yao YP (2008). Protective effects of ethanolic extracts of buckwheat groats on DNA damage caused by hydroxyl radicals. Food Res. Int. 41: 924-929.

Chan YS and Ng TB (2013) A lectin with highly potent inhibitory activity toward breast cancer cells from edible tubers of Dioscorea opposita cv. Nagaimo. PLoS One 8: e54212.

Cui XD and Wang ZH (2012). Preparation and properties of rutin-hydrolyzing enzyme from tartary buckwheat seeds. Food Chem. 132: 60-66.

Dhuna V, Bains JS, Kamboj SS, Singh J, et al. (2005). Purification and characterization of a lectin from Arisaema tortuosum Schott having in-vitro anticancer activity against human cancer cell lines. J. Biochem. Mol. Biol. 38: 526-532.

Fabjan N, Rode J, Kosir IJ, Wang Z, et al. (2003). Tartary buckwheat (Fagopyrum tataricum Gaertn.) as a source of dietary rutin and quercitrin. J. Agric. Food Chem. 51: 6452-6455.

Frankfurt OS and Krishan A (2003). Apoptosis-based drug screening and detection of selective toxicity to cancer cells. Anticancer Drugs 14: 555-561.

Fujital K, Inoue N, Yang ZF, Hagiwara S, et al. (2003). Varietal differences of antioxidant activity in Tartary buckwheat flour as evaluated by chemiluminescence. Fagopyrum 20: 47-52.

Gemeiner P, Mislovicová D, Tkác J, Svitel J, et al. (2009). Lectinomics II. A highway to biomedical/clinical diagnostics. Biotechnol. Adv. 27: 1-15.

Herre J, Willment JA, Gordon S and Brown GD (2004). The role of Dectin-1 in antifungal immunity. Crit. Rev. Immunol. 24: 193-203.

Hilder VA, Powell KS, Gatehouse AMR, Gatehouse JA, et al. (1995). Expression of snowdrop lectin in transgenic tobacco plants results in added protection against aphids. Transgenic Res. 4: 18-25.

Ivory CP and Chadee K (2007). Activation of dendritic cells by the Gal-lectin of Entamoeba histolytica drives Th1 responses in vitro and in vivo. Eur. J. Immunol. 37: 385-394.

Jin HM and Wei P (2011). Anti-fatigue properties of tartary buckwheat extracts in Mice. Int. J. Mol. Sci. 12: 4770-4780.

Kaliński P, Hilkens CM, Snijders A, Snijdewint FG, et al. (1997). IL-12-deficient dendritic cells, generated in the presence of prostaglandin E2, promote type 2 cytokine production in maturing human naive T helper cells. J. Immunol. 159: 28-35.

Kammanadiminti SJ, Mann BJ, Dutil L and Chadee K (2004). Regulation of Toll-like receptor-2 expression by the Gallectin of Entamoeba histolytica. FASEB J. 18: 155-157.

Kaur A, Singh J, Kamboj SS, Sexana AK, et al. (2005). Isolation of an N-acetyl-D-glucosamine specific lectin from the rhizomes of Arundo donax with antiproliferative activity. Phytochemistry 66: 1933-1940.

Kawakmi A, Kayahara H and Ujihara A (1995). Properties and elimination of bitter components derived from tartary buckwheat (Fagopyrum tataricum) flour. J. Jpn. Soc. Food Sci. 42: 892-898.

Laemmli UK (1970). Cleavage of structural proteins during the assembly of the head of bacteriophage T4. Nature 227: 680-685.

Li DY, Gu C, Min J, Chu ZH, et al. (2012). Maturation induction of human peripheral blood mononuclear cell-derived dendritic cells. Exp. Ther. Med. 4: 131-134.

Liu XQ, Wu H, Yu HL, Zhao TF, et al. (2011). Purification of a lectin from Arisaema erubescens (Wall.) Schott and its pro-inflammatory effects. Molecules 11: 9480-9494.

Nakagawa R, Yasokawa D, Ikeda T and Nagashima K (1996). Purification and characterization of two lectins from callus of Helianthus tuberosus. Biosci. Biotechnol. Biochem. 60: 259-262.

Obeid M, Tesniere A, Ghiringhelli F, Fimia GM, et al. (2007). Calreticulin exposure dictates the immunogenicity of cancer cell death. Nat. Med. 13: 54-61.

Reed JC (2001). Apoptosis-regulating proteins as targets for drug discovery. Trends Mol. Med. 7: 314-319.

Rubinstein N, Ilarregui JM, Toscano MA and Rabinovich GA (2004). The role of galectins in the initiation, amplification and resolution of the inflammatory response. Tissue Antigens 64: 1-12.

Sallusto F, Cella M, Danieli C and Lanzavecchia A (1995). Dendritic cells use macropinocytosis and the mannose receptor to concentrate macromolecules in the major histocompatibility complex class II compartment: downregulation by cytokines and bacterial products. J. Exp. Med. 182: 389-400.

Stein GM, Büssing A and Schietzel M (2002a). Activation of dendritic cells by an aqueous mistletoe extract and mistletoe lectin-3 in vitro. Anticancer Res. 22: 267-274.

Stein GM, Büssing A and Schietzel M (2002b). Stimulation of the maturation of dendritic cells in vitro by a fermented mistletoe extract. Anticancer Res. 22: 4215-4219.

Svensson M, Stockinger B and Wick MJ (1997). Bone marrow-derived dendritic cells can process bacteria for MHC-I and MHC-II presentation to T cells. J. Immunol. 158: 4229-4236. 
Tesniere A, Panaretakis T, Kepp O, Apetoh L, et al. (2008) Molecular characteristics of immunogenic cancer cell death. Cell Death Differ. 15: 3-12.

Tomotake H, Yamamoto N, Yanaka N, Ohinata H, et al. (2006). High protein buckwheat flour suppresses hypercholesterolemia in rats and gallstone formation in mice by hypercholesterolemic diet and body fat in rats because of its low protein digestibility. Nutrition 22: 166-173.

Trinchieri G (2003). Interleukin-12 and the regulation of innate resistance and adaptive immunity. Nat. Rev. Immunol. 3 : 133-146.

Trinchieri G (2007). Interleukin-10 production by effector T cells: Th1 cells show self control. J. Exp. Med. 204: 239-243.

Tsai YC, Jeng CR, Hsiao SH, Chang HW, et al. (2010). Porcine circovirus type 2 (PCV2) induces cell proliferation, fusion, and chemokine expression in swine monocytic cells in vitro. Vet. Res. 41: 60.

Vandenborre G, Smagghe G and Van Damme EJM (2011). Plant lectins as defense proteins against phytophagous insects. Phytochemistry 72: 1538-1550.

Vaz AFM, Costa RMPB, Melo AMMA, Oliva MLV, et al. (2010). Biocontrol of Fusarium species by a novel lectin with low ecotoxicity isolated from Sebastiania jacobinensis. Food Chem. 119: 1507-1513.

Vicari AP, Caux C and Trinchieri G (2002). Tumour escape from immune surveillance through dendritic cell inactivation. Semin. Cancer Biol. 12: 33-42.

Yagi F, Iwaya T, Haraguchi T and Goldstein IJ (2002). The lectin from leaves of Japanese cycad, Cycas revoluta Thunb. (gymnosperm) is a member of the jacalin-related family. Eur. J. Biochem. 269: 4335-4341. 